\title{
Importância da inter-relação carboidrato e proteína em dietas de ruminantes
}

\section{Importance of interrelation carbohydrate and protein in diets of ruminants}

\section{Elzânia Sales Pereira ${ }^{1 *}$; Alex Martins Varela de Arruda ${ }^{2}$; Lídia Ferreira Miranda Ivone Yurika Mizubuti'; Elaine Barbosa Muniz ${ }^{5}$; Andréa Pereira Pinto ${ }^{6}$}

\begin{abstract}
Resumo
Esta revisão de literatura teve como objetivo relacionar a importância da sincronização de carboidratos e proteínas em dietas de ruminantes, pois os sistemas de exigências nutricionais de ruminantes que dão suporte às formulações de rações exigem que os alimentos comumente utilizados na alimentação sejam fracionados no sentido de melhor caracterizá-los. Ao longo dos anos houve considerável avanço na nutrição dos ruminantes, mas esse progresso, na maioria das vezes, foi baseado em determinações empíricas que desconsideravam as múltiplas inter-relações microbianas e consideravam o ecossistema ruminal muito complexo e não compreendido.
\end{abstract}

Palavras-chave: Energia, proteína, ruminantes, sistema cornell.

\begin{abstract}
This literature review had as objective to relate the importance of the carbohydrate and protein synchronization in ruminant diets. The nutritional requirements systems to ruminant that give support to the diets formulations, require that the feeds commonly used in the feeding are fractional for best characterize them. Along the years there was considerable progress in the ruminant nutrition, but that progress, most of the time, was based on empiric determinations that not respected the multiple microbial interrelations and they considered the ruminal ecosystem are very complex and not understood.
\end{abstract}

Key-words: Energy, protein, ruminants, cornell system.

1 Professora do Curso de Zootecnia, UNIOESTE - PR, Campus de Marechal Cândido Rondon. e- mail: elzania@hotmail.com

2 Professor do Curso de Zootecnia, UNIOESTE - PR, Campus de Marechal Cândido Rondon. e- mail: amvarela39@hotmail.com

3 Professora da Faculdade de Estudos Administrativos de Minas Gerais. Belo Horizonte, MG.

4 Professora do Departamento de Zootecnia do Centro de Ciências Agrárias da UEL- PR, Londrina, PR. e-mail: mizubuti54@hotmail.com ou mizubuti@uel.br

5 Professora do Curso de Zootecnia, UNIOESTE - PR, Campus de Marechal Cândido Rondon. e-mail: ebmuniz@unioeste.br

6 Doutoranda do Programa de Pós-graduação em Ciência Animal da Universidade Estadual de Londrina, Londrina, PR.

* Autor para correspondência 


\section{Introdução}

A determinação do valor nutritivo de alimentos destinados à alimentação de animais ruminantes tem sido alvo de contínuos trabalhos de pesquisa. Observa-se constante procura de metodologias acuradas e simples para estimar a qualidade dos alimentos, cujos objetivos são as predições dos valores protéicos e energéticos para atender a demanda gerada pelas funções produtivas dos animais em determinado estágio fisiológico. O problema essencial é a busca do entendimento em bases mecanicistas das relações entre a composição bromatológica, a disponibilidade de energia e proteína e as respostas esperadas nos animais. Para o entendimento de como os alimentos utilizados na alimentação devem ser fracionados para sua adequada caracterização, são feitas inicialmente algumas considerações sobre as frações dos alimentos que constituem as fontes de nitrogênio $(\mathrm{N})$ e de energia para os ruminantes. Posteriormente, é discutida a importância entre a sincronização desses nutrientes como meio de maximizar a produção microbiana e consequentemente a produção animal.

\section{Formas do Nitrogênio e dos Carboidratos nos Alimentos}

Existem diferenças marcantes, conforme a espécie, em relação à dependência dietética das diferentes categorias de nutrientes especificados a seguir: nutrientes plásticos (proteínas); nutrientes energéticos (que incluem proteínas, carboidratos e lipídeos); nutrientes inorgânicos ou minerais; e vitaminas.

A maioria dos microorganismos pode sintetizar aminoácidos a partir de precursores simples como a amônia. Os animais superiores, por outro lado, não podem sintetizar certos aminoácidos classificados como essenciais. Este fato, no entanto, não torna obrigatório atribuir a determinadas espécies de animais superiores como os ruminantes e os tilópodos, uma relativa dependência dietética por determinados nutrientes. Os ruminantes podem ser considerados animais relativamente independentes da qualidade dos compostos nitrogenados consumidos porque são dotados de segmentos gástricos que evoluíram para acomodar populações complexas de microorganismos sob anaerobiose. Os ruminantes utilizam os alimentos através da fermentação pré-gástrica e da digestão intestinal. A retenção dos alimentos no rúmen submete-os à ação de microbiota diversa que existe neste compartimento gástrico. Nos últimos anos tem havido um interesse considerável na redução das perdas de nitrogênio pelos ruminantes, a partir de formulações de dietas balanceadas que considerem as múltiplas inter-relações entre os microrganismos ruminais e o hospedeiro. As adequações das dietas teriam como funções: a minimização das perdas nitrogenadas pelos animais, a maximização do crescimento das bactérias ruminais e a melhoria no desempenho dos animais. Se for feita uma analogia em relação ao material consumido que chega ao estômago simples dos não ruminantes (particularmente no que diz respeito aos carboidratos e proteínas), a digesta que chega no abomaso é completamente diferente do material ingerido pelo ruminante. O processamento ruminal reduz drasticamente a disponibilidade de carboidratos, o que exige do animal a gênese de glicose a partir de compostos não carboidratados (gliconeogênese). Desta forma, os eventos digestivos, tais como: assimilação, utilização e excreção de compostos nitrogenados dos animais ruminantes, não podem ser considerados como eventos mutuamente exclusivos, mas sim como parte de um sistema totalmente integrado, que evoluiu por milhares de anos até se constituir nos organismos que hoje, aparentemente conhecemos.

Atualmente os sistemas de avaliação de alimentos para ruminantes que dão suporte à formulação de rações exigem que os alimentos utilizados pelos animais sejam fracionados no sentido de melhor caracterizá-los (SNIFFEN, et. al., 1992). A fração protéica dos alimentos pode ser fracionada em componentes A (fração solúvel - nitrogênio não protéico (NNP)), $B_{1}$ (fração solúvel rapidamente 
degradada no rúmen), $\mathrm{B}_{2}$ (fração insolúvel, com taxa de degradação intermediária no rúmen), $\mathrm{B}_{3}$ (fração insolúvel lentamente degradada no rúmen) e fração C que é indigestível durante sua permanência no trato gastrintestinal.

As frações nitrogenadas têm sido determinadas através de métodos de solubilização, entretanto, a estimativa de suas respectivas taxas de digestão tem sido obtidas através de diferentes métodos, resultando em grande variação nos resultados obtidos. Os métodos mais utilizados têm sido o "in situ" e o "in vitro" com proteases oriundas de Streptomyces griseus (KRISNAMOORTHY et al., 1983). A ação das proteases originárias dessa bactéria apresenta atividade máxima para os estudos de degradação protéica em pH 8,0 (KRISNAMOORTHY et al., 1983), daí decorrem as críticas com relação ao uso dessas enzimas para obtenção das taxas de degradação (BRODERICK, 1994). Entretanto, Kohn e Allen (1995) propuseram um método "in vitro" com proteases isoladas de microrganismos do rúmen, possibilitando a sua utilização para estimativa das taxas de digestão das frações protéicas lentamente digeríveis, tornando esta uma alternativa interessante ao uso das proteases comerciais. Considerando os custos de obtenção, seria adequada a utilização das enzimas isoladas do rúmen, que podem ser obtidas no próprio laboratório (KOHN; ALLEN, 1995; MALAFAIA; VALADARES FILHO; VIEIRA, 1997; PEREIRA et al. 2000).

Os carboidratos também podem ser fracionados em componentes $A$ (açúcares solúveis com rápida degradação ruminal), $\mathrm{B}_{1}$ (amido e pectina) e $\mathrm{B}_{2}$ (correspondente a fibra potencialmente degradável com taxa de degradação mais lenta) e C que apresenta característica de indigestibilidade. Este sub-fracionamento foi descrito por Sniffen et al., (1992), sendo objeto de entrada de dados para o sistema Cornell Net Carbohydrate And Protein System (CNCPS). Este sistema tem como objetivos estimar as taxas de degradação ruminal de diferentes subfrações dos alimentos; maximizar a sincronização de proteínas e carboidratos no rúmen e conseqüentemente a produção microbiana, além de minimizar as perdas nitrogenadas (SNIFFEN et al., 1992).

No Brasil, a utilização deste sistema para predizer o desempenho animal, deverá ser feita a partir do sub-fracionamento dos carboidratos e proteínas que compõem os alimentos, e o conhecimento do comportamento destas frações ao longo do trato gastrintestinal (PEREIRA et al., 2000). No futuro, em função da utilização de modelos ou sistemas que venham predizer e explicar satisfatoriamente os eventos digestivos, a produção de alimentos e a utilização dos nutrientes resultará em minimização dos recursos financeiros e viabilização de recursos naturais (FOX; BARRY, 1995).

Os procedimentos para a determinação da solubilidade da proteína têm sido recomendados como rotina laboratorial prévia aos estudos de degradabilidade da proteína bruta (MADSEN; HVELPLUND, 1994). No entanto, a extração do nitrogênio por meio de tampões não permite discriminar que porção é constituída de nitrogênio não protéico e qual é a de natureza verdadeiramente protéica (VAN SOEST, 1994). Além disso, tem sido relatada na literatura a existência de uma associação positiva entre a degradação da proteína bruta e sua solubilidade; contudo, tal observação empírica carece de entendimento mais detalhado das características cinéticas das diferentes fontes protéicas dos alimentos. Por exemplo, as proteínas de alfafa são desnaturadas pelo processo de fenação, apresentando considerável redução na solubilidade e, no entanto, continuam a apresentar elevada degradação no rúmen. Por outro lado, o tratamento prévio para se obter a farinha de sangue reduz drasticamente a solubilidade das albuminas de natureza altamente solúvel, permanecendo inalterada a sua característica original de baixa degradação ruminal (BRODERICK, 1994; VAN SOEST, 1994).

A interpretação cinética dos dados de degradação de proteína dos alimentos deve ser baseada na distinção entre o nitrogênio solúvel nos ácidos 
tricloroacético (TCA) ou wolfrâmico $\left(\mathrm{H}_{2} \mathrm{WO}_{4}\right)$ e o nitrogênio insolúvel residual após o tratamento com estes compostos. O último representa as porções verdadeiramente protéicas, potencialmente digeríveis $\left(\mathrm{B}_{1}, \mathrm{~B}_{2}\right.$ e $\left.\mathrm{B}_{3}\right)$ e indigerível (c) dos alimentos (SNIFFEN et al., 1992; VAN SOEST, 1994; LICITRA; HERNANDEZ; VAN SOEST, 1995). Os sistemas de alimentação de ruminantes necessitam dos conhecimentos das taxas de digestão dos alimentos que normalmente compõe suas rações para adequação nitrogenada no rúmen e intestino.

\section{Proteína e Carboidrato: sistema integrado na nutrição de ruminantes}

Os alimentos, quando consumidos pelos ruminantes são transformados pelos microrganismos ruminais. Esta transformação resulta em confundimento para a predição do desempenho animal a partir dos componentes dietéticos (RUSSELL et al., 1992).

A digestão nos compartimentos gástricos e nos segmentos iniciais do intestino delgado tem como função a redução das formas poliméricas complexas em substâncias simples (monossacarídeos e aminoácidos) para serem assimilados ao longo do trato gastrintestinal. Os processos de digestão e fermentação executados pelos microrganismos ruminais fornecem os produtos finais da fermentação (ácidos graxos voláteis), que são utilizados como fonte de energia, e a massa microbiana cuja constituição protéica representa uma fonte de aminoácidos para o hospedeiro.

O sistema CNCPS sugere a divisão do ecossistema ruminal em dois grupos microbianos, ou seja, os microrganismos que utilizam carboidratos estruturais, e aqueles que utilizam carboidratos não estruturais. Esta segregação reflete diferenças quanto as fontes de energia e compostos nitrogenados utilizados, bem como a eficiência do crescimento microbiano. As bactérias que fermentam carboidratos estruturais necessitam de amônia como principal fonte de $\mathrm{N}$ e ácidos graxos de cadeia ramificada.
Estes microrganismos não utilizam peptídeos e aminoácidos; quando em condições limitantes de $\mathrm{N}$, apresentando menor crescimento, decorrentes dos maiores custos de manutenção. As bactérias que fermentam carboidratos não estruturais apresentam crescimento mais rápido e utilizam em média $66 \%$ de peptídeos e aminoácidos e 34\% de amônia para o seu crescimento (RUSSELL et al., 1992).

Os microrganismos ruminais dependem de esqueletos de carbono, disponibilidade de energia e de um concomitante fornecimento de amônia e peptídeos para que haja síntese microbiana. A disponibilidade de carboidratos no rúmen é muito importante e tem grande efeito sobre a utilização dos compostos nitrogenados; pois as bactérias ruminais podem incorporar os aminoácidos e fermentá-los como fonte de energia. Através da manipulação da relação volumoso:concentrado é possível alterar os processos fermentativos e maximizar a eficiência de síntese microbiana, bem como a eficiência de utilização dos nutrientes dietéticos (RUSSELL et al.,1992). O crescimento microbiano depende da transferência de energia da fermentação de carboidratos para o processo biossintético, por exemplo, de síntese de proteína microbiana. O processo catabólico (fermentação de carboidratos) é completamente vinculado ao processo anabólico (síntese microbiana) via adenosina tri fosfato (ATP). Se a taxa de produção de ATP excede a taxa de utilização, ocorre desacoplamento energético, e a energia da ATP é dissipada como calor através de ciclos de íons pela membrana celular. Isto ocorre quando a disponibilidade de $\mathrm{N}$ é extremamente alta (ou a energia está em excesso, quando do uso de altos níveis de concentrado), ou se minerais como enxofre (S) e fósforo (P) estão deficientes (NOCEK; RUSSELL, 1988). Geralmente, quando carboidratos são limitantes, os aminoácidos dietéticos são usados como fonte de energia, ocorrendo acúmulo de amônia (RUSSELL et al., 1992). Portanto, a adição de carboidratos, além de promover síntese de proteína microbiana, exerce um efeito poupador de aminoácidos (NOCEK; RUSSELL, 1988). 
A extensão com que os nutrientes são degradados é determinada pela competição entre a taxa de passagem e de degradação, com efeitos profundos sobre o desempenho animal; sendo que o conhecimento de ambas é necessário para predizer a quantidade de energia ou proteína que estão disponíveis no rúmen.

Os sistemas de avaliação de alimentos para ruminantes empregam modelos de primeira ordem para estimar a digestão e o escape ruminal dos nutrientes. O conhecimento atual dos padrões cinéticos dos nutrientes no rúmen, de acordo com Mertens (1993), se deu em função do desdobramento conceitual da celulose proposto por Waldo (1986). A manipulação das taxas de digestão e de passagem pode culminar em maior ou menor escape de proteína dietética, que resulta em formas diferentes de utilização de compostos nitrogenados dietético pelos animais (VAN SOEST, 1994).

A proteína dietética pode ser mais ou menos destruída, mas o crescimento microbiano pode compensar a perda de qualidade. Quando a proteína é consumida em excesso, o nitrogênio dietético é convertido em amônia, que é absorvida pelo epitélio ruminal e excretada na forma de uréia pelos rins. Por outro lado, dietas pobres em nitrogênio são enriquecidas pelo processamento ruminal, levando um maior e melhor aporte de aminoácidos para os intestinos (VAN SOEST, 1994; BRODERICK, 1994).

A proteína microbiana sintetizada no rúmen fornece $50 \%$ ou mais dos aminoácidos disponíveis para a absorção, em rações balanceadas, sendo considerada uma fonte de aminoácidos de alta qualidade (SCHWAB, 1996). As diferentes porções das frações protéicas digestíveis que escapam à degradação ruminal constituem o total de aminoácidos que chegam ao intestino delgado.

Vários sistemas de exigências protéicas utilizam valores de 0,8 a 0,85 para a digestibilidade intestinal aparente da proteína não degradada no rúmen, sendo o valor de 0,80 adotado pelo National Research
Council - NRC (1985). O valor de 0,9 X (proteína não degradada no rúmen (PNDR) - 6,25 nitrogênio insolúvel em detergente ácido (NIDA)) é o valor utilizado pelo Agricultural And Food Research Council (1993) e os valores de 1,00; 1,00 e 0,80 são utilizados para as frações $\mathrm{B}_{1}, \mathrm{~B}_{2}$ e $\mathrm{B}_{3}$, respectivamente, pelo sistema CNCPS. Vale ressaltar que a eficiência de síntese de proteína microbiana tem sido expressa de diferentes formas: O NRC (1985) considerou a produção de proteína bruta bacteriana em função de nutrientes digestíveis totais (NDT); o Agricultural Research Council (1984) expressou em relação à matéria orgânica degradada no rúmen (MODR); o Agricultural and Food Research Council (1993) considerou a eficiência em função da energia metabolizável fermentada no rúmen, e o CNCPS, descrito por Russell et al., (1992), expressou a eficiência microbiana em grama de matéria seca bacteriana (gMSbac) por grama de carboidratos totais degradados no rúmen (CHODR).

O termo proteína metabolizável (PM) é aplicado ao total de aminoácidos absorvidos pelo animal sendo correspondente à proteína verdadeira microbiana e a proteína dietética digestíveis que escaparam da degradação ruminal (AGRICULTURAL AND FOOD RESEARCH COUNCIL, 1993; VAN SOEST, 1994), e pode ser calculada da seguinte forma (SNIFFEN et al., 1992):

$$
\mathrm{PM}=\left[\mathrm{P}_{\mathrm{B}} \times \mathrm{f}_{\mathrm{B}} \times 0,01+\sum_{\mathrm{i}=1}^{3}\left(\mathrm{~EB}_{\mathrm{i}} \times \mathrm{f}_{\mathrm{i}} \times 0,01\right)\right]-\left(\mathrm{N}_{\mathrm{AN}} \times 6,25\right)
$$

onde, $\mathrm{P}_{\mathrm{B}}\left(\mathrm{g} \mathrm{d}^{-1}\right)$ representa o montante de proteína bruta bacteriana que chega ao intestino delgado; $\mathrm{f}_{\mathrm{B}}$ (\%) corresponde ao coeficiente de digestibilidade da proteína bruta bacteriana; $\mathrm{EB}_{\mathrm{i}}\left(\mathrm{g} \mathrm{d}^{-1}\right)$ corresponde ao escape das respectivas frações verdadeiramente protéicas, para $i=1,2$ e 3 , multiplicadas pelos seus respectivos coeficientes de digestibilidade, $\mathrm{f}_{\mathrm{i}}(\%)$; e $\mathrm{N}_{\mathrm{AN}}\left(\mathrm{g} \mathrm{d}^{-1}\right)$ equivale ao aporte de ácidos nucléicos no intestino delgado, para o qual é pressuposto um coeficiente de digestibilidade de $100 \%$.

Uma forma mais eficiente de incorporação do carbono de aminoácidos da proteína bacteriana se 
dá pela assimilação de peptídeos (NOLAN, 1993). No entanto, se a taxa de proteólise for muito elevada e o consumo de matéria seca for o suficiente para reduzir o tempo de retenção dos compostos nitrogenados no rúmen, a formação de peptídeos pode ser favorável se a proteína dietética for de boa qualidade, dado o maior escape de tais compostos para o intestino delgado (RUSSELL et al., 1992; NOLAN, 1993; VAN SOEST, 1994). Portanto, podese assegurar que as taxas de degradação e de passagem têm efeito profundo sobre os produtos finais da fermentação e sobre o desempenho animal. Frente a isto, Russell et al. (1992) relataram que: (1) se a taxa de degradação da proteína exceder à taxa de degradação dos carboidratos, grandes quantidades de nitrogênio podem ser perdidas na forma de amônia; (2) se a taxa de degradação de carboidratos for menor do que a das proteínas ocorre uma redução no crescimento microbiano; (3) se os alimentos são degradados lentamente no rúmen, ocorre aumento do efeito de repleção ruminal; e (4) se a taxa de degradação for lenta, pode haver um maior escape de nutrientes para o intestino delgado. A adição de fontes de proteína verdadeira degradável no rúmen, em dietas pobres em carboidratos não estruturais e suficientes em nitrogênio não protéico, pode resultar em respostas significativas por parte do animal. A assimilação de aminoácidos e de ácidos graxos de cadeia ramificada oriundos destas fontes protéicas, satisfaz as exigências das bactérias utilizadoras de carboidratos estruturais por tais fatores de crescimento (RUSSELL et al., 1992; VAN SOEST, 1994).

A razão entre aminoácidos essenciais e os não essenciais ganha importância na porção protéica que escapa à degradação ruminal, uma vez que o perfil de aminoácidos da proteína solúvel é transformado naquele verificado na proteína microbiana. Através de manipulação, por tratamentos físico ou químico das fontes protéicas, ou pelo fornecimento de fontes protéicas que variem no grau de degradação, podese obter maior aporte de aminoácidos para o intestino delgado (BRODERICK, 1994; VAN SOEST, 1994).
Entretanto, os benefícios de tais procedimentos são controversos na literatura. A ausência de resposta tem sido atribuída a vários fatores que incluem: redução na síntese de proteína microbiana; suprimento de pequenas quantidades de proteína em relação às exigências; rações com níveis elevados de proteína em relação às exigências e baixa disponibilidade intestinal. Por outro lado se o teor de nitrogênio, for limitante para os microrganismos devido à menor degradação da proteína, a eficiência de crescimento pode ser comprometida. Santos et al. (1998) realizaram ampla revisão sobre o assunto, e verificaram que a utilização de suplementos com elevado escape ruminal da proteína não resultaram em maior consumo voluntário, bem como maiores fluxos de $\mathrm{N}$ microbiano para o abomaso, quando comparada às dietas contendo uréia ou fontes protéicas de alta degradação.

A partir das revisões de Nocek e Russelll (1988), Russell et al. (1992), Sniffen et al. (1992) e Broderick (1994), é possível afirmar que para a correta utilização do conceito de proteína degradável e não degradável no rúmen são necessários: (1) estimativas exatas das características cinéticas das frações protéicas dos alimentos; (2) o conhecimento dos efeitos do consumo voluntário ou da taxa de passagem sobre a cinética de degradação protéica; (3) a determinação da melhor forma de utilização do nitrogênio pela reciclagem endógena e (4) o conhecimento das exigências em aminoácidos para o atendimento dos processos de manutenção e produção.

\section{Exigências de Aminoácidos Para Ruminantes}

As exigências de proteína dos animais ruminantes são atendidas pelos aminoácidos absorvidos no intestino delgado, denominadas de exigências de proteína metabolizável. A proteína que chega ao intestino delgado consiste da fração microbiana, da proteína dietética não degradada no rúmen e da proteína endógena. A estabilidade relativa do perfil de aminoácidos da proteína microbiana torna difícil a 
alteração do perfil de aminoácidos da digesta duodenal (STERN et al.,1994), sendo necessário para essa alteração, o fornecimento de fontes de proteína não degradada em proporções substanciais de proteína dietética. Considerando que a proteína microbiana é de alta qualidade, torna-se importante maximizar sua síntese no rúmen (VALADARES FILHO; VALADARES, 2001). Outra fonte de aminoácidos disponíveis para a absorção é a PNDR. Todos os alimentos geralmente contêm alguma PNDR e em contraste com a proteína microbiana, existem grandes diferenças na qualidade da PNDR. A maior variação no perfil de aminoácidos essenciais que deixam o rúmen deve-se à quantidade e proporção desses aminoácidos na PNDR (SCHWAB, 1996).

O perfil de aminoácidos do material original e da PNDR tem sido investigado por diferentes pesquisadores (VARVIKKO, 1986; CROOKER et al., 1987; HARSTAD; PRESTLOKKEN, 2000; TEDESCKI et al., 2001), resultando em grande variação nos resultados obtidos. Os métodos mais utilizados para tais estudos incluem métodos "in vitro" ou "in situ", e as variações obtidas tem sido, portanto, atribuídas às diferenças metodológicas (RODRIGUEZ, 1996); à contaminação microbiana do material incubado e ao desaparecimento do substrato incubado no rúmen (TEDESCKI et al., 2001).

Os requisitos nutricionais de animais de alta produção freqüentemente excedem à capacidade de síntese protéica e fermentação ruminal. Quando a proteína não degradável da dieta é aumentada, o balanço de aminoácidos desta parcela torna-se muito importante. Com isso, a seleção de proteínas de várias fontes é freqüentemente necessária para assegurar a absorção com um adequado balanceamento de aminoácidos (PALMQUIST; WEISBJERG; HVELPLUND, 1993).

A necessidade de identificação dos aminoácidos essenciais mais limitantes em animais leiteiros de alta produção tem sido sugerida a alguns anos (JARRIGE, 1987). Vários pesquisadores sugeriram que a metionina e a lisina são os aminoácidos mais limitantes para a produção de leite (SCHWAB, 1996; SUSMEL et al., 1989; RULQUIN; VÉRITÉ, 1996). Para bezerros em crescimento sugeriram a metionina, a lisina e a treonina como primeiro, segundo e terceiro aminoácidos limitantes, respectivamente (RICHARDSON; HATFIELD, 1978; OWENS; ZINN, 1993). Em vitelos consideraram como limitantes os aminoácidos sulfurados, a lisina e, provavelmente, a treonina (WILLIAMS, 1994). Entretanto, a resposta produtiva, aos aminoácidos considerados limitantes nos ruminantes, é menos consistente do que aquela obtida para as aves (OLDHAM, 1993).

Sloan, Garthwaite e Schwab (1998) afirmaram que existem duas possibilidades de formular dietas com lisina e metionina digestíveis: o sistema francês (PDI) e o sistema americano originário do CNPS e concluíram que o balanceamento de rações considerando esses aminoácidos digestíveis geralmente resulta em aumentos nos teores de proteína bruta (PB) do leite de 0,1 a 0,2 /unidades percentuais e a produção de leite em até $4 \%$ no início da lactação. Para maximizar o retorno econômico, recomendaram utilizar 6,82 e $2,19 \%$ da proteína metabolizável para os respectivos teores de lisina e metionina digestíveis e que uma relação de 3,1: 1 de lisina : metionina digestíveis deve ser respeitada. Além disso, os autores também recomendaram usar o preço por grama de metionina digestível em vez do preço/ $\mathrm{kg}$ do produto contendo metionina protegida.

Somente os aminoácidos na forma L são constituintes de proteínas (STRYER, 1998), com exceção da parede celular bacteriana, que pode ser constituída também de aminoácidos na forma de Disômeros. No organismo animal, D-aminoxidases podem catabolizar D-aminoácidos, produzindo cetoácidos que serão transaminados para produzir L-isômeros e serem aproveitados no metabolismo. Nos tecidos animais não são verificados transaminases para lisina e treonina, tornando os Disômeros destes aminoácidos nutricionalmente inativos (BUTTERY; D’MELLO, 1994). Talvez a ausência de transaminases para lisina no organismo animal, possa explicar, em parte, o fato de que a lisina 
seja um aminoácido limitante para ruminantes. Outra possibilidade está relacionada à dieta básica de muitos rebanhos, as quais são constituídas principalmente de silagem de milho, que apresenta baixos teores de lisina em sua composição protéica (RULQUIN; VÉRITÉ, 1996).

A disponibilidade de aminoácidos para produção de leite pode ser maximizada pelo incremento da ingestão de alimentos, pela otimização da fermentação ruminal, pelo crescimento microbiano e pela suplementação protéica ou de aminoácidos na dieta que escapa à fermentação ruminal e sobrepassa ao intestino delgado. Aminoácidos dietéticos que escapam à fermentação ruminal poderiam complementar aqueles fornecidos pelas proteínas microbianas (CLARK; KLUSMEYER; CAMERON 1992).

Alguns resultados de pesquisa sugerem que o perfil de aminoácidos dos alimentos, na fração protéica não degradada no rúmen, possa ser modificado após a sua exposição à fermentação ruminal e ao ataque microbiano, quando comparado ao alimento original (CROOKER et al., 1986, 1987; SUSMEL et al., 1989; CHEN; ORSKOV, 1994; ERASMUS et al., 1994). O grau destas alterações pode diferir de alimento para alimento (RULQUIN; VÉRITÉ, 1996), entretanto, devido à deficiência de dados na literatura, tem-se considerado que todos os aminoácidos sejam igualmente susceptíveis à degradação ruminal.

O perfil de aminoácidos disponíveis para absorção intestinal está relacionado à composição de aminoácidos da dieta, à quantidade de proteína não degradável e à quantidade de proteína microbiana. Vários pesquisadores julgam oportuna a correção, para a contaminação microbiana, dos valores de aminoácidos dos resíduos da incubação ruminal (ROOKE; GREIFE; ARMSTRONG, 1984; CROOKER et al., 1986, 1987; VARVIKKO, 1986), embora Valadares Filho et al. (1992) a considerem essencial somente para alguns tipos de alimentos. Em alimentos ricos em proteínas a contaminação microbiana apresenta, provavelmente, pequena influência na composição de $\mathrm{N}$ e de aminoácidos no resíduo não degradado no rúmen. Maiores contaminações são encontradas em alimentos com alto conteúdo de parede celular e baixos teores de nitrogênio (VARVIKKO, 1986).

Dessa forma, em qualquer sistema ou modelo matemático adotado, há necessidade do conhecimento da composição dos alimentos, das taxas de degradação ruminal dos nutrientes ou de suas frações, da taxa de passagem, das quantidades de proteína microbiana sintetizadas e de aminoácidos absorvidos no intestino delgado (FOX; BARRY, 1995).

\section{Conclusões}

A maximização da sincronização de proteína e carboidratos dietéticos no rúmen resulta na minimização das perdas nitrogenadas e aumento da produção microbiana com conseqüente aumento do processo produtivo. No Brasil, como os volumosos apresentam baixos teores protéicos, possivelmente os níveis adequados de proteína em rações de ruminantes sejam diferentes daqueles estipulados pelos sistemas de exigências nutricionais que dão suporte às formulações de rações.

\section{Referências}

AGRICULTURAL AND FOOD RESEARCH COUNCIL. Energy and protein requirements of ruminants. Cambridge: CAB International, 1993. 159p.

AGRICULTURAL RESEARCH COUNCIL. The Nutrient Requirements of Ruminant Livestock. London: Common Wealth Agriculture Bureaux, Farnham Royal, 1984. Supp. $1.350 \mathrm{p}$.

BRODERICK, G.A. Quantifying forage protein quality. In: FAHEY JR., G.C. (Ed.). Forage quality, evaluation, and utilization. Madison: American Society of Agronomy, 1994. p.200-228.

BUTTERY, P. J.; D'MELLO, J. P. F. Amino acid nutrition in sheep. In: D'MELLO, J. P. F.(Ed). Amino acid in farm animal nutrition. Wallingford: CAB, 1994. p.307-328. 
CHEN, X. B.; ORSKOV, E. R. Amino acid nutrition in farm animal: An overview. In: D’MELLO, J. P. F. (Ed). Amino acid in farm animal nutrition. Wallingford: CAB, 1994. p.1-10.

CLARK, J.H.; KLUSMEYER, T.H.; CAMERON, M.R. Microbial protein synthesis and flows of nitrogen fractions to duodenum of dairy cows. Journal of Dairy Science, Champaign, v. 75, n. 8, p. 2304-2323, 1992.

CROOKER, B. A.; CLARK,J. H.; SHANKS, R. D.; FAHEY G. C. Effects of ruminal exposure on the amino acid profile of feeds. Canadian Journal of Animal Science, Ottawa, v. 67, n. 4, p. 1143-1148, 1987.

CROOKER, B. A.; CLARK,J. H.; SHANKS, R. D.; HATFIELD, E. E. Effects of ruminal exposure on the amino acid profile of heated and formaldehyde-treated soybeanmeal. Journal of Dairy Science, Champaign, v. 69, n. 10, p. 2648-2657, 1986.

ERASMUS, L. J.; BOTHA, P. M.; CRUYWAGEN, C. W.; MEISSNER, H. H. Amino acid profile and intestinal digetibility in dairy cows of rumen- undegradable protein from various feedstuffs. Journal of Dairy Science, Champaign, v. 77, n. 2, p. 541-551, 1994.

FOX, D. G.; BARRY, M. C. Predicting nutrient requirements and supply for cattle with the Cornell net carbohydrate and protein system. In: SIMPÓSIO INTERNACIONAL SOBRE EXIGÊNCIAS NUTRICIONAIS DE RUMINANTES. 1995, Viçosa. Anais ... Viçosa: Universidade Federal de Viçosa, 1995. p. 77-101.

HARSTAD, O.M.; PRESTLOKKEN, E. Effective rumen degradability and intestinal indigestibility of individual amino acids in solvent- exttracted soybean meal (SBM) and xylose-treated SBM (Soypass (R)) determined in situ. Animal Feed Science and Tecnology. Netherlands, v. 83, n. 1, p.31-47, 2000.

JARRIGE, R. Situation and perspectives of the modern protein feeding systems of ruminants. In: SEMINAR IN THE COMMUNITY PROGRAMME FOR THE COORDINATION OF AGRICULTURAL RESEARCH, 1987, Brussels. Feed evaluation and protein requirement systems for ruminants. Brussels: Commission of the European Communities, 1987. p. 305-326.

KOHN, R. A.; ALLEN, M. S. In vitro protein degradation of feeds using concentrated enzymes extracted from rumen contents. Animal Feed Science and Technology, Netherlands, v. 52, n. 1-2, p. 15-28, 1995.

KRISHNAMOORTHY, U.; SNIFFEN, C. J.; STERN, M. D.; VANSOEST, P. J. Evaluation of a mathematical model of rumen digestion and an in vitro simulation of rumen proteolysis to estimate the rumen-undegraded nitrogen content of feedstuffs. British Journal of Nutrition, Wallingford, v. 50,n. 3, p. 555-568, 1983.
LICITRA, G.; HERNANDEZ, T. M.; VAN SOEST, P. J. Standardization of procedures for nitrogen fractionation of ruminant feeds. Animal Feeds Science and Technology, Netherlands, v. 57, n. 4, p. 347-358. 1995.

MADSEN, J.; HVELPLUND, T. Prediction of in situ protein degradability in the rumen: results of an european ringtest. Livestock Production Science, Netherlands, v. 39, n. 2, p. 201-212, 1994.

MALAFAIA, P. A. M.; VALADARES FILHO, S. C.; VIEIRA, R. A. M. Determinação e cinética ruminal das frações protéicas de alguns alimentos para ruminantes. Revista Brasileira de Zootecnia, Viçosa, v. 26, n. 6, p. 1243-1251. 1997.

MERTENS, D. R. Kinetics of cell wall digestion and passage in ruminants. In: JUNG, H. G.; BUXTON, D. R.; HATFIELD, R. D.; RALPH, J. (Ed.). Forage cell wall structure and digestibility. Madison: Wisconsin American Society of Agronomy, 1993. p. 535-570.

NATIONAL RESEARCH COUNCIL. Ruminant nitrogen usage. Washington: Nacional Acedam of Sciences, 1985. $138 \mathrm{p}$.

NOCEK, J. E.; RUSSELL, J. B. Protein and energy as an integrated system. Relationship of ruminal protein and carbohydrate availability to microbial synthesis and milk production. Journal of Dairy Science, Champaign, v. 71, n. 8, p. 2070-2107, 1988.

NOLAN, J. V. Nitrogen Kinetics. In: FORBES, J. M.; FRANCE, J. Quantitative aspects of ruminant digestion and metabolism. Wallingford: Cambridge University, 1993, p. 123-144.

OLDHAM, J. D. Recent progress towards matching feed quality to the amino acid needs of ruminants. Animal Feed Science and Technology, Netherlands, v. 45, n. 1, p. 19-34, 1993.

OWENS, F. N.; ZINN, R. Metabolismo de la proteina los ruminantes. In: CURCH, D. C. (Ed.). El ruminant fisiologia digestiva y nutrition. Zaragoza: Acribia, 1993. p. 255-282.

PALMQUIST, D. L.; WEISBJERG, M. R.; HVELPLUND, T. Ruminal intestinal, and total digestibilities of nutrients in cows fed diets hight in fat and undegradable protein. Journal of Dairy Science, Champaign, v. 76, n. 5, p. 13531364, 1993.

PEREIRA, E. S.; QUEIROZ, A. C.; VALADARES FILHO, S. C.; PAULINO, M. F.; CECON, P. R.; MIRANDA, L. F.; FERNANDES, A. M.; CABRAL, L. S. Determinação das frações protéicas e de carboidratos e taxas de degradação in vitro da cana-de-açúcar, da cama de frango e do farelo de algodão. Revista Brasileira de Zootecnia, Viçosa, v. 29, n. 6, p 1887-1893, 2000. 
RICHARDSON, C. R.; HATFIELD, E. E. The limiting amino acid growing cattle. Journal of Animal Science, Savoy, v. 46, n. 3, p. 740-749, 1978.

RODRIGUEZ, N. M. Exigências em aminoácidos para vacas de alta produção. In: SIMPÓSIO LATINO AMERICANO DE NUTRIÇÃOANIMAL E SEMINÁRIO SOBRE TECNOLOGIAS DE PRODUÇÃO DE RAÇÕES, 1996, Campinas. Anais... Campinas: CBNA, 1996. p. 103-137.

ROOKE,J. A.; GREIFE, H. A.; ARMSTRONG, D. G. The effect of insacco rumen incubation of a grass silage upon the total and D-amino-acid composition of the residual silage dry matter. Journal of Agricultural Science, New York, v. 102, p. 695-702, 1984.

RULQUIN, H.; VÉRITÉ, R. Amino acid nutrition of dairy cows: productive effects and animal requirements. In: GARNSWORTHY, P. C.; COLE, D. J. A. (Ed.) Recent developments in animal nutrition. Nottingham: University Press, 1996. p. 71-94.

RUSSELL, J.B.; O'CONNOR, J.D.; FOX,D. G.; VAN SOEST, P. J.; SNIFFEN, C. J. A net carbohydrate and protein system for evaluating cattle diets. 1. Ruminal fermentation. Journal of Animal Science, Savoy, v. 70, n. 11, p. 35513561, 1992.

SANTOS, F. A. P.; SANTOS, J. E. P; THEURER, C. B.; HUBER, J. T. Effects of rumen-undegradable protein on dairy cow performance: a 12-year literature review. Journal of Dairy Science, Savoy, v. 81, n.12, p. 3182-3213, 1998.

SCHWAB, C. G. Amino acid nutrition of the dairy cow:Current status. In: PROCEEDINGS CORNELL NUTRITION CONFERENCE FOR FEED MANUFACTURES, 1996, Ithaca. Proceedings... Ithaca: Cornell University, 1996. p.184-198.

SLOAN, B.K.; GARTHWAITE, B. D.; SCHWAB, C. G. Practical formulation of dairy cow diets for digestible amino acid to improve nitrogen efficiency and botton line. In: PROCEEDING CORNELL NUTRITION CONFERENCE FOR FEED MANUFACTURES, 1998, Ithaca. Proceedings... Ithaca, 1998. p. 51-64.

SNIFFEN, C. J.; O’CONNOR, J. D.; VAN SOEST, P. J.; FOX, D. G.; RUSSELL, J. B. A net carbohydrate and protein system for evaluating cattle diets: II. Carbohydrate and protein availability. Journal of Animal Science, Savoy, v. 70, n. 12, p. 3562-3577, 1992.
STERN, M.D.; VARGA, G .A.; CLARK, J .H.; FIRKINS, J. L.; HUBER, J. T.; PALMQUIST, D. L. Evaluation of chemical and physical properties of feeds that affect protein metabolism in the rumen. Journal of Dairy Science, Champaign, v. 77, n. 9, p. 2762-2786, 1994.

STRYER, L. Bioquímica. 3. ed. Rio de Janeiro: Guanabara Koogan, 1998

SUSMEL, P.; STEFANON, B.; MILLS, C. R.; CANDIDO, $\mathrm{M}$. Change in amino acid composition of different protein sources after rumen incubation. Animal Production, Scotland, v. 49, p. 375-383, 1989.

TEDESCHI, L. O.; PELL, A. N.; FOX, D. G.; LLAMES, C. R. The amino acid profiles of the whole plant and of four plant residues from temperature and tropical forages. Journal of Animal Science, Savoy, v. 79, n. 5, p.525-532, 2001.

VALADARES FILHO, S. C.; COELHO SILVA, J. F.; SANT'ANNA; LEÃO, M. I.; VALADARES, R. D. F.; RAJÃO, D. C. Degradabilidade "in situ" aparentes e corrigidas e composição de aminoácidos da proteína não degradada do rúmen de vários alimentos. Revista da Sociedade Brasileira de Zootecnia, Viçosa, v. 21, n. 4, p. 744-760, 1992.

VALADARES FILHO, S. C.; VALADARES, R. F. D. Recentes avanços em proteína na nutrição de vacas leiteiras. In: SINLEITE- BOVINOCULTURA DE LEITE: NOVOS CONCEITOS EM NUTRIÇÃO, 2., 2001, Lavras. Anais... Lavras: UFLA, 2001. p. 229-248.

VAN SOEST, P. J. Nutritional ecology of the ruminant. 2.ed.; Ithaca, New York: Cornell University, 1994. 476 p.

VARVIKKO, T. Microbially corrected amino acid compsoition of rumen-undegraded feed protein and amino acid degradability in the rumen of feeds enclosed in nylon bags. British Journal of Nutrition, Wallingford, v. 56, n. 1, p. 131-140, 1986.

WALDO, D. R. Effect of forage quality on intake and forage-concentrate interactions. Journal of Dairy Science, Champaign, v. 69, n. 2, p. 617-631, 1986.

WILLIAMS, A. P. Amino acid requirements of the veal calf and beef steers. In: D'MELLO, J. P. F. (Ed.). Amino acid in farm animal nutrition. Wallingford: $\mathrm{CAB}, 1994$. $\mathrm{p}$. 329-350. 